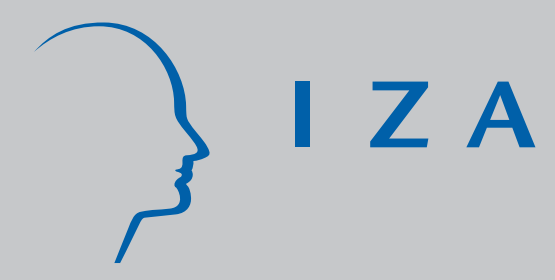

IZA DP No. 2309

The Speed of Employer Learning and J ob Market Signaling Revisited

Steffen Habermalz

September 2006 


\title{
The Speed of Employer Learning and Job Market Signaling Revisited
}

\author{
Steffen Habermalz \\ Northwestern University \\ and IZA Bonn
}

\section{Discussion Paper No. 2309 \\ September 2006}

\author{
IZA \\ P.O. Box 7240 \\ 53072 Bonn \\ Germany \\ Phone: +49-228-3894-0 \\ Fax: +49-228-3894-180 \\ Email: iza@iza.org
}

\begin{abstract}
Any opinions expressed here are those of the author(s) and not those of the institute. Research disseminated by IZA may include views on policy, but the institute itself takes no institutional policy positions.

The Institute for the Study of Labor (IZA) in Bonn is a local and virtual international research center and a place of communication between science, politics and business. IZA is an independent nonprofit company supported by Deutsche Post World Net. The center is associated with the University of Bonn and offers a stimulating research environment through its research networks, research support, and visitors and doctoral programs. IZA engages in (i) original and internationally competitive research in all fields of labor economics, (ii) development of policy concepts, and (iii) dissemination of research results and concepts to the interested public.
\end{abstract}

IZA Discussion Papers often represent preliminary work and are circulated to encourage discussion. Citation of such a paper should account for its provisional character. A revised version may be available directly from the author. 
IZA Discussion Paper No. 2309

September 2006

\section{ABSTRACT \\ The Speed of Employer Learning and Job Market Signaling Revisited}

This paper discusses the claim made in Altonji and Pierret (1997) and Lange (2005) that a high speed of employer learning indicates a low value of job market signaling. The claim is first discussed intuitively in light of Spence's original model and then evaluated in a simple extension of a model developed in Altonji and Pierret (1997). The analysis provided indicates that, if employer learning is incomplete, a high speed of employer learning is not necessarily indicative of a low value of job market signaling.

JEL Classification: $\quad$ I20, D8, J41

Keywords: employer learning, signaling

Corresponding author:

Steffen Habermalz

Northwestern University

Department of Economics

3224 Andersen Hall

2001 Sheridan Road

Evanston IL 60208

USA

E-mail: s-habermalzs@northwestern.edu 


\section{Introduction}

Ever since the seminal Nobel Prize winning works of Akerloff (1970), Spence (1973), and Stiglitz (1975) economists have shown great interest in the effects of asymmetric information on economic outcomes. In the field of labor economics there has been an ongoing and vibrant discussion centered on the information asymmetries between hiring firms and prospective workers.

Job Market Signaling (JMS), introduced by Spence (1973), proposes that highability workers differentiate themselves from observationally identical workers of lower ability by acquiring an educational signal which is observed by potential employers. If higher ability individuals find it less costly (both in monetary and non-monetary terms) to acquire an educational degree this process will lead to a separating equilibrium in which workers can be differentiated by their signals.

A related approach was introduced by Farber and Gibbons (1996) and further developed by Altonji and Pierret (1997 and 2001). In their models of Employer Learning (EL) they assume that employers statistically discriminate among prospective workers on the basis of a signal (usually education) which is related to the (unobserved) ability of a worker. Models of EL predict that information indicative of a worker's true productivity but only observed by the econometrician will be increasingly correlated with wages as the worker gains more labor market experience. The model also predicts that the estimated returns to education will decline with labor market experience when such a measure is included in the regression equation. Intuitively this happens because the employer receives (noisy) signals of a worker’s true productivity and learns over time. Thus, actual information on the true productivity of the worker accrues over time and the 
educational signal loses value. Altonji and Pierret (1997 and 2001) test this prediction using scores of the Armed Forces Qualification Test (AFQT) administered to participants in the National Longitudinal Survey of Youth 1979 (the measure only observed by the econometrician) and find both hypothesis empirically confirmed. Altonji and Pierret (1997, hereafter AP) also investigate the relationship between the speed of employer learning and the value of Job Market Signaling. The paper develops a simple signaling model in which employers learn very quickly. AP show that, in such a setting, workers only have an incentive to acquire education if the returns are exorbitantly high. They conclude that the value of signaling cannot be very high if employers learn quickly.

Extending the Employer Learning literature Lange (2005) estimates the speed at which employers learn about workers' true productivities. He concludes that employer learning is rather fast and, partially based on the argument provided by AP, uses this result to downplay the economic significance of JMS.

The contribution of this paper is to provide a different interpretation of results of Lange (2005) and AP and challenge the contention that a high speed of employer learning is indicative of a low value of signaling. The paper proceeds as follows: using insights from Spence (1973), Section 2 of the paper provides a descriptive and intuitive discussion of the signaling process as it pertains to the claims made in Lange (2005) and AP. In the simple quantitative analysis of Section 3 I extend AP's model by introducing the (realistic) possibility that EL is incomplete. The results of a simulation provide evidence for an important role of JMS even if employer learning is very fast. In accordance with the discussion in Section 2 the results also hint at the possibility that a higher speed of employer learning might increase the value of JMS. Section 3 attempts to reconcile the 
contrasting views by discussing the relationship between the speed of EL and the existence of JMS. Section 4 concludes.

\section{The Speed of EL and the Value of JMS: An Intuitive Discussion}

Lange (2005) estimates the speed at which employers learn and finds that employers are able to reduce their average expectation error concerning the productivity of a worker by $50 \%$ over the first 3 years. He concludes (probably correctly) that this is rather fast. He then argues, partially based on the argument provided in AP, that Job Market Signaling is of limited value.

In Spence (1973) employers hire workers according to educational signals that are correlated with the workers' true productivity. In equilibrium the employers' beliefs about the informational content of the educational signals are confirmed. In order to achieve equilibrium and react to changes in the productivity/signal relationship it should be beneficial for employers to have their beliefs confirmed sooner rather than later.

Figure 1 schematically illustrates the signaling process. Thus the findings of Lange (2005) imply that this process works rather efficiently and that employers need not wait long to confirm their hiring practices. It also implies that it does not take them long to detect workers that, for whatever reason, obtained the wrong signal and "masquerade" as high ability workers. This means that employers would rather learn quickly than slow and that the value of the educational signal should be positively correlated with the speed of employer learning. It also shows that employers would not value the JMS process if it would take a long time for their beliefs to be confirmed since it would be harder to detect underperforming workers and would render hiring based on educational signals less 
efficient. The value of the signal to employers depends on their ability to select individuals of a particular productivity, the more efficient this mechanism works, the better.

Lange (2005) supplements his in-depth mathematical treatment with a graphical analysis of the relationship between the speed of employer learning and the value of signaling. Figure 2 reproduces his graph (Figure 3 in Lange (2005)). The figure shows two average productivity paths, a low one for low ability workers and a higher one for high ability workers. It also shows two earnings paths (dashed lines) for a low productivity worker who (wrongly) decides to go to college corresponding to two different speeds of employer learning. The area between the lower solid line and the dashed lines corresponds to the return to acquiring the college degree. It is clear from the graph that a higher speed of employer learning will limit the worker's return. Lange uses this argument to show the inverse relationship between the speed of employer learning and the value of an educational signal. While the graph seems intuitive, a different interpretation is forwarded here. The return shown is not the return to an educational signal originating in the JMS model. It is the return to an out-of-equilibrium choice of schooling. The person shown in the graph is "masquerading" as a high-ability worker. The JMS provides the means to overcome informational asymmetries by providing an educational signal which enables employers to separate observationally identical individuals into ability groups. The earlier individuals with the "wrong” signal can be detected, the more efficient the process of JMS is, implying that a higher speed of EL is beneficial. The above applies to workers with signals indicating productivities higher or lower than their actual productivities. Therefore, a higher speed of EL can be thought of 
as decreasing the variance of the employers estimator of workers' true productivities. It makes the process more efficient. The results provided in Lange (2005) can thus be interpreted as evidence that a higher speed of EL makes JMS more valuable.

\section{The Speed of EL and the Value of JMS: Extending AP's Model}

AP's argument is based on the following model: Assume that there are 2 types of workers, 0 and 1, with productivities $\mathrm{Y}_{1}$ and $\mathrm{Y}_{0}\left(\mathrm{Y}_{1}>\mathrm{Y}_{0}\right)$. The labor market is competitive so that workers are paid their expected productivity. Individuals choose between one year of schooling or no schooling at all. Schooling costs are higher for type 0 . In signaling equilibrium $(1+\mathrm{k})=\mathrm{Y}_{1} / \mathrm{Y}_{0}$ represents the ratio of productivities of the two types of workers. Employers learn nothing for two years and then instantly acquire full information about the productivity of their workers. With zero interest rates this implies that the present value for a $\mathrm{Y}_{1}$ type without schooling is

$$
\operatorname{PV}\left(\mathrm{Y}_{1} \text {, No School }\right)=2 \mathrm{Y}_{0}+(\mathrm{T}-2)(1+\mathrm{k}) \mathrm{Y}_{0}
$$

The present value of $\mathrm{Y}_{1}$ with one year of schooling (no earnings while in school) is equal to.

$$
(\mathrm{T}-1)(1+\mathrm{k}) \mathrm{Y}_{0}
$$

This implies that type $\mathrm{Y}_{1}$ will choose school if

$$
\begin{gathered}
(\mathrm{T}-1)(1+\mathrm{k}) \mathrm{Y}_{0}>2 \mathrm{Y}_{0}+(\mathrm{T}-2)(1+\mathrm{k}) \mathrm{Y}_{0} \text { or } \\
\mathrm{k}>1 .
\end{gathered}
$$

Type $\mathrm{Y}_{1}$ individuals choose schooling only if they are paid twice as much as type $\mathrm{Y}_{0}$. Since empirical estimates of the returns to schooling are in the roughly between 5\%- 
$10 \%$ AP reject the notion that the signaling value of education plays a significant role in determining the value of education in the labor market if employers learn sufficiently fast about workers’ productivities.

To summarize, in AP’s model a high productivity worker has two choices. He can attend school and, upon graduation, work for a high wage firm. The second possibility is not to attend school and, after a short stint at a low wage firm and upon the revelation of his true productivity, move to a high wage firm. The empirical ramifications of this process are somewhat disconcerting. Taken literally instant and complete revelation of a worker's true productivity unconditional on her current job would enable a worker to work in the food service industry for a short time before an instantaneous transfer into investment banking. While it is certainly not inconceivable that some workers in low paying jobs have the ability to be investment bankers, it seems very unlikely that employer information acquired in the low-wage job will pave the way. To achieve the same occupational success the worker in AP's model has to choose between putting in effort and acquiring an educational signal or staying in a low-paying job for a short time. In this environment it is obvious that only a very high wage differential could induce individuals to consider going to school at all and the speed of employer learning would indeed be inversely related to the signaling value of education. The following analysis will show that AP's model is an extreme case of a more general model that does not imply that JMS is of low value.

AP assume that EL is symmetric and complete. The former implies that the current employers do not have more information than potential employers. The latter 
assumes that an employer is able to obtain complete information about a worker's true productivity. I will maintain the assumption of symmetric learning.

Aside from the pure ability to learn does an employer have an incentive to learn everything about a worker? The answer to this question depends on which talents are important to the firm. In general, it seems safe to assume that an employer is only interested in how much a certain worker fulfills her current job requirement (and maybe the requirements for a certain track). This implies that the firm most likely does not have an incentive to learn about a worker's ability completely, implying a limit in most cases. In addition Lange (2005) estimates that even with a high speed of employer learning, and after 40 years in the labor market, employers will only know 93\% of the true productivity of a worker. How would such a limit on learning affect the conclusions drawn by AP? We can augment AP's model by assuming that, after L years (two in AP's model), the employer will know a fraction $(1-\alpha)<1$ of the worker's true productivity. The model also allows for variable learning and schooling parameters. Therefore, a type $\mathrm{Y}_{1}$ individual who chooses $\mathrm{S}$ years of schooling will have lifetime earnings equal to

$$
(T-S) \cdot(1+k) \cdot Y_{0}
$$

where $\mathrm{T}$, as before, is the number of time periods and $\mathrm{S}$ represents the number of years of schooling $^{1}$. If the individual chooses no schooling his lifetime earnings are

$$
L \cdot Y_{0}+(T-L) \cdot\left[\alpha \cdot Y_{0}+(1-\alpha) \cdot(1+k) \cdot Y_{0}\right]
$$

Noting the that k needs to be adjusted for years of education, solving for $\mathrm{k}$ yields

$$
k=\left(\frac{L+(T-L) \cdot \alpha}{(T-S)-(T-L) \cdot(1-\alpha)}-1\right) \cdot \frac{1}{S}
$$

\footnotetext{
${ }^{1}$ It is assumed that the individual either chooses 0 or $\mathrm{S}$ years of schooling.
} 
Note that AP's model is a special case in which $\mathrm{S}=1$ and $\alpha=0$. To analyze the model Table 1 shows the average return to schooling necessary to induce an individual to choose schooling for different values of schooling and employer learning. Table 2 shows the minimum alpha (max. amount of EL) necessary to achieve empirically relevant returns to education of $10 \%$.

The simulations in Table 1 show that (given alpha=1/3 and $\mathrm{T}=40$ ) limiting learning reduces the return necessary to induce an individual to attend school to a reasonable range. The results also show that, conditional on attending school, the return to an educational signal increases with the speed of employer learning. Table 2 provides more general results. It displays the alpha necessary to generate an average return to schooling equal to $10 \%$. Note that an alpha $=0$ implies that employers will have all information at the end of L years. It is a remarkable property of the model that, even if learning only takes one year, employers are allowed to learn between 60 and 75 percent of a workers ability without requiring the return to the educational signal to exceed empirical values. This necessary value far exceeds Lange’s estimate (50\% after 3 years) and shows that JMS is potentially valuable even when the speed of employer learning is high.

\section{The Speed of EL and the Existence of JMS}

One can potentially reconcile the conclusions of this papers with the views expressed in AP and Lange (2005) by examining the relationship between the speed of EL and the existence of JMS. Imagine a world in which EL is extremely slow. 
Considering the inability of employers to confirm their beliefs (detect out-of-equilibrium choices) under such a regime it is very likely that JMS would not exist. Employers, on the other hand, would value an efficient signaling process highly. Furthermore, there is no room for JMS in a world where employers learn about the true productivity of a worker instantaneously after hiring. Employers would not be willing to pay much for a signal. Observing the speed of EL and the value of JMS in both worlds leads us to believe that there is a negative correlation between the two. However, it does not make sense to discuss this relationship in scenarios in which potentially JMS does not exist. The argument of this paper is that, if JMS exists, one should expect that a higher speed of EL does not imply a low value of JMS. Figure 3 illustrates this.

\section{Conclusion}

This paper provides evidence that challenges the views expressed in Altonji and Pierret (1997) and Lange (2005) that a high speed of employer learning implies a low value of job market signaling. It was first shown qualitatively that the postulated relationship seems at odds with Spence's original model. Furthermore, the paper illustrated that, when perceiving employer learning as an imperfect process with a sufficient degree of residual long-term uncertainty, the conclusion of Altonji and Pierret (1997) fails to hold. The main result of the paper is thus that the relationship between the speed of employer learning and the value of job market signaling cannot be determined

without further inquiry. Based on the discussion in the paper future work should identify the relationship between the speed of employer learning and the existence of job market signaling in order to cast more light on the issue. 


\section{References}

Altonji, Joseph, G., and Charles Pierret. 1997 .Employer Learning and the Signaling Value of Education. In Industrial Relations, Incentives and Employment, edited by I. Ohashi and T. Tachibanaki. London: Macmillan Prese Ltd.: 159-95.

Altonji, Joseph G., and Charles R. Pierret. 2001. Employer Learning and Statistical Discrimination, Quarterly Journal of Economics 116: 313-50.

Akerlof, George A. 1970. The Market for “Lemons”: Quality Uncertainty and the Market Mechanism, Quarterly Journal of Economics 84: 488-500.

Farber, Henry S., and Robert Gibbons. 1996. Learning and Wage Dynamics. Quarterly Journal of Economics 111: 1007-47.

Lange, Fabian. 2005. The Speed of Employer Learning. Journal of Labor Economics, forthcoming.

Spence, A. Michael. 1973. Job Market Signaling. Quarterly Journal of Economics $87: 355-74$

Stiglitz, Joseph E. 1975. The Theory of “Screening”, Education, and the Distribution of Income. American Economic Review 65: 283-300. 
Figure 1

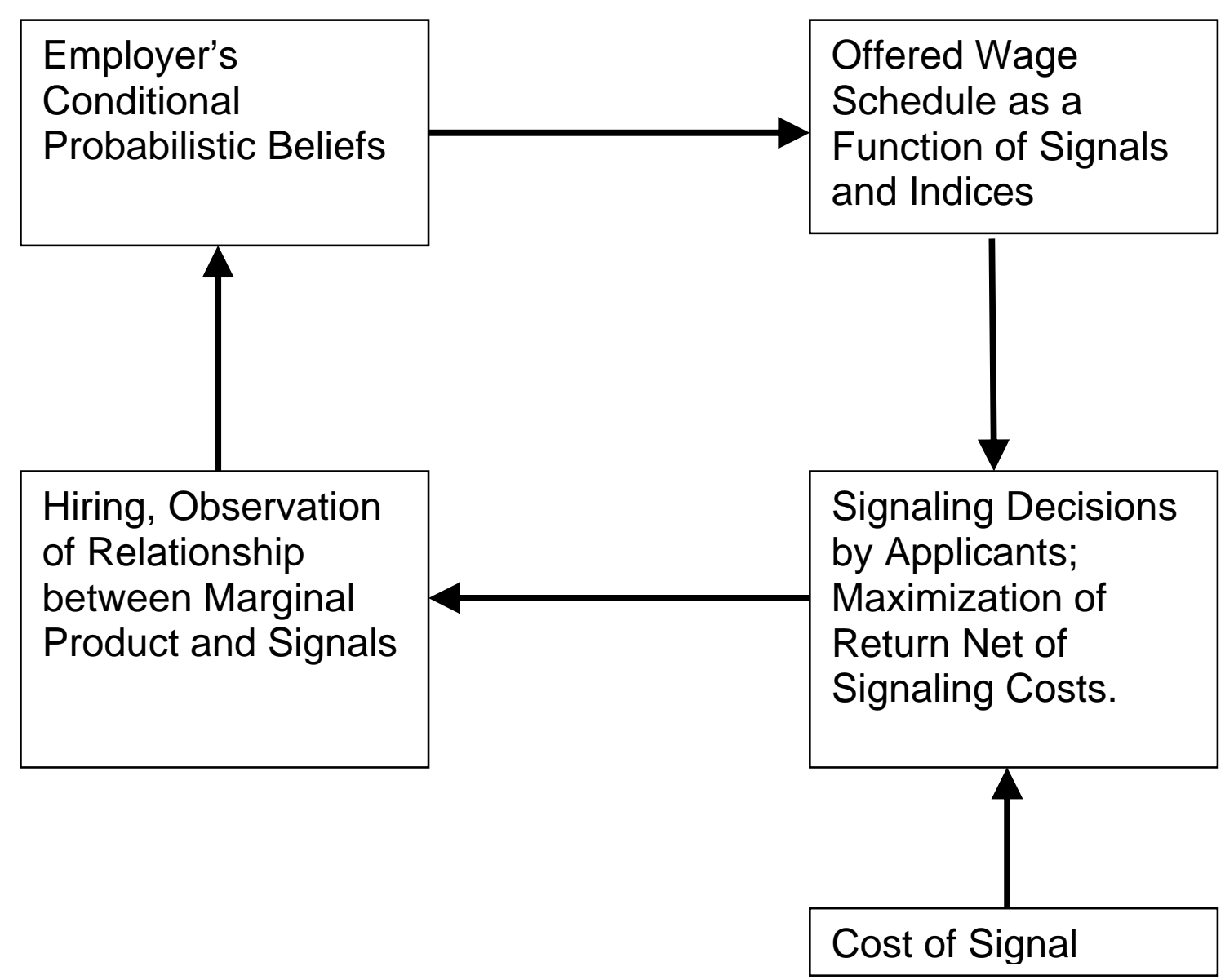

Source: Spence (1973) 
Table 1: Simulated Average Return to Schooling (\%)

(alpha=1/3, $t=40$ )

Years of Education

\begin{tabular}{rr|cccccc} 
& & 1 & 2 & 3 & 4 & 5 & 6 \\
\hline \hline & 1 & 10.26 & 11.43 & 12.90 & 14.81 & 17.39 & 21.05 \\
$\mathrm{~L}$ & 2 & 9.52 & 10.53 & 11.76 & 13.33 & 15.38 & 18.18 \\
$\mathrm{e}$ & 3 & 8.89 & 9.76 & 10.81 & 12.12 & 13.79 & 16.00 \\
$\mathrm{a}$ & 4 & 8.33 & 9.09 & 10.00 & 11.11 & 12.50 & 14.29 \\
$\mathrm{r}$ & 5 & 7.84 & 8.51 & 9.30 & 10.26 & 11.43 & 12.90 \\
$\mathrm{n}$ & 6 & 7.41 & 8.00 & 8.70 & 9.52 & 10.53 & 11.76 \\
$\mathrm{i}$ & 7 & 7.02 & 7.55 & 8.16 & 8.89 & 9.76 & 10.81 \\
$\mathrm{n}$ & 8 & 6.67 & 7.14 & 7.69 & 8.33 & 9.09 & 10.00 \\
$\mathrm{~g}$ & 9 & 6.35 & 6.78 & 7.27 & 7.84 & 8.51 & 9.30 \\
& 10 & 6.06 & 6.45 & 6.90 & 7.41 & 8.00 & 8.70
\end{tabular}

Table 2: Minimum Alpha Necessary

for $10 \%$ Average Return to Schooling $(t=40)$

\begin{tabular}{rr|cccccc} 
& \multicolumn{7}{c}{ Years of Education } \\
& & 1 & 2 & 3 & 4 & 5 & 6 \\
\hline \hline & 1 & 0.26 & 0.28 & 0.31 & 0.33 & 0.36 & 0.38 \\
$\mathrm{~L}$ & 2 & 0.24 & 0.26 & 0.29 & 0.32 & 0.34 & 0.37 \\
$\mathrm{e}$ & 3 & 0.22 & 0.24 & 0.27 & 0.30 & 0.32 & 0.35 \\
$\mathrm{a}$ & 4 & 0.19 & 0.22 & 0.25 & 0.28 & 0.31 & 0.33 \\
$\mathrm{r}$ & 5 & 0.17 & 0.20 & 0.23 & 0.26 & 0.29 & 0.31 \\
$\mathrm{n}$ & 6 & 0.15 & 0.18 & 0.21 & 0.24 & 0.26 & 0.29 \\
$\mathrm{i}$ & 7 & 0.12 & 0.15 & 0.18 & 0.21 & 0.24 & 0.27 \\
$\mathrm{n}$ & 8 & 0.09 & 0.13 & 0.16 & 0.19 & 0.22 & 0.25 \\
$\mathrm{~g}$ & 9 & 0.06 & 0.10 & 0.13 & 0.16 & 0.19 & 0.23 \\
& 10 & 0.03 & 0.07 & 0.10 & 0.13 & 0.17 & 0.20
\end{tabular}




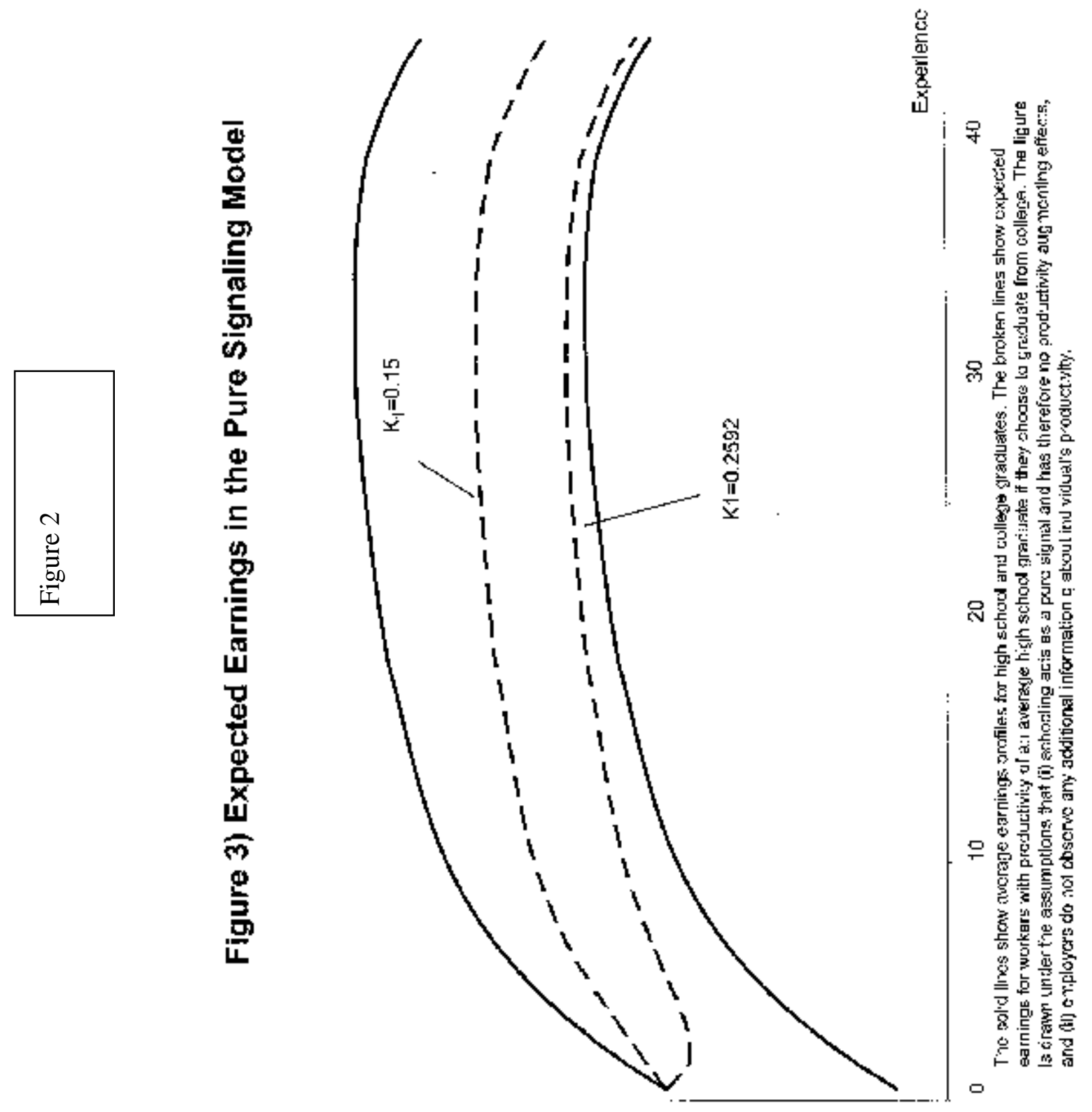


Figure 3

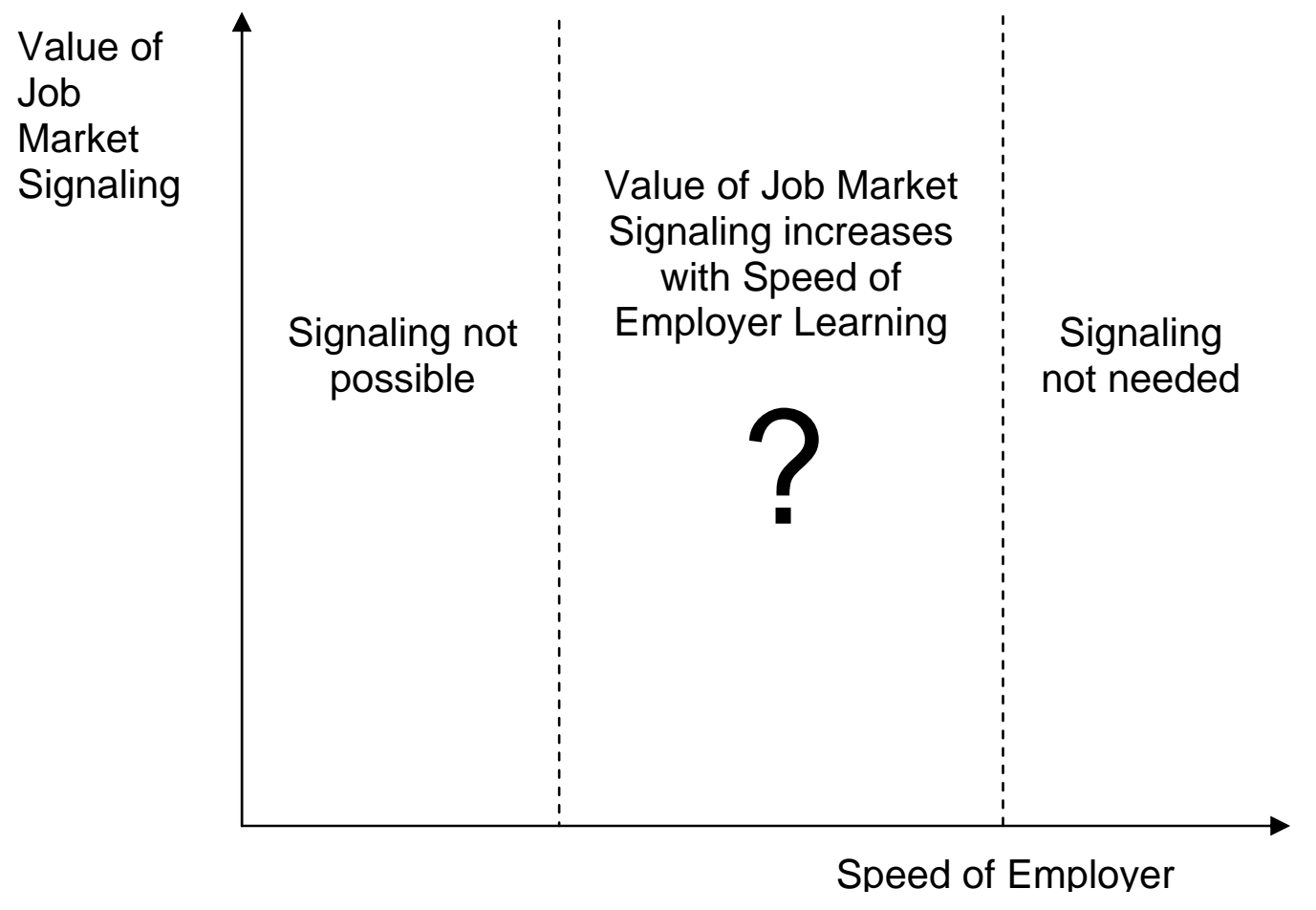

